\title{
S0 I-04 OA. Phenotypic analyses of CD8+ T cells that mediate virus inhibition from HIV-I vaccinees and HIV-I+ virus controllers
} SA Freel*1, PK Chattopadhyay², L Lamoreaux ${ }^{3}$, D Zarkowsky33, RG Overman ${ }^{4}$, C Ochsenbauer-Jambor ${ }^{5}$, JC Kappes ${ }^{5}$, CK Cunningham ${ }^{6}$, TN Denny ${ }^{7}$, KJ Weinhold ${ }^{8}$, G Ferrari ${ }^{9}$, RA Koup ${ }^{3}$, BS Graham ${ }^{10}$, BF Haynes ${ }^{11}$, M Roederer ${ }^{2}$ and GD Tomaras ${ }^{12}$

Address: ${ }^{1}$ DHVI and Surgery, Duke University Medical School, Durham, USA, ${ }^{2}$ ImmunoTechnology Section, Vaccine Research Center, NIAID, NIH, Bethesda, MD, USA, ${ }^{3}$ Immunology Core Section, Vaccine Research Center, NIAID, NIH, Bethesda, MD, USA, ${ }^{4}$ Duke University Medical Center; DHVI and Surgery, Durham, NC, USA, ${ }^{5}$ University of Alabama, Department of Medicine, Birmingham, AL, USA, ${ }^{6}$ Duke University Medical Center, Department of Pediatrics, Durham, NC, USA, ${ }^{7}$ Duke University Medical Center; DHVI and Medicine, Durham, NC, USA, ${ }^{8}$ Duke University Medical Center; DHVI, Immunology and Surgery, Durham, NC, USA, ${ }^{9}$ Duke University Medical Center; Department of Surgery, Durham, NC, USA, ${ }^{10}$ Viral Pathogenesis Laboratory; Vaccine Research Center, NIAID, NIH, Bethesda, MD, USA, ${ }^{1}$ Duke University Medical Center; DHVI, Immunology, and Medicine, Durham, NC, USA and ${ }^{12}$ Duke University Medical Center, DHVI, Surgery and Immunology, Durham, NC, USA

* Corresponding author

from AIDS Vaccine 2009

Paris, France. 19-22 October 2009

Published: 22 October 2009

Retrovirology 2009, 6(Suppl 3):OI doi:I0.II86/1742-4690-6-S3-OI

This abstract is available from: http://www.retrovirology.com/content/6/S3/O I

(C) 2009 Freel et al; licensee BioMed Central Ltd.

\section{Background}

CD8-mediated virus inhibition can be detected in HIV-1+ subjects controlling virus replication in the absence of ART. Characterizing the $\mathrm{CD} 8^{+} \mathrm{T}$ cells that mediate virus inhibition is important for determining the nature of $\mathrm{CD}^{+} \mathrm{T}$ cells that need to be elicited by an HIV-1 vaccine.

\section{Methods}

We used a 3-day CD8+ $\mathrm{T}$ cell mediated virus inhibition assay (CD8 VIA) to assess CD8 ${ }^{+}$function. Primary CD4+ enriched lymphocytes were infected with reporter viruses expressing transmitted/founder envelopes in the presence of serial dilutions of autologous $\mathrm{CD} 8^{+} \mathrm{T}$ cells. We examined activated CD8 ${ }^{+} \mathrm{T}$ cells from 22 HIV-1+ subjects (of which 15 were virus controllers (VC)), 37 HIV-1 vaccinees (DNA prime, rAd5 boost encoding HIV-1 Env and GagPol) and 6 seronegative donors. Phenotypic analysis of HIV-1 specific CD $8^{+}$cells was determined by 13 color flow cytometry. Phenotypically-defined $\mathrm{CD}^{+} \mathrm{T}$ cell subsets from selected donors were sorted by flow cytometry and tested for virus suppression.

\section{Results}

VCs had robust antiviral activity against both transmitted/ founder and NL4-3 enveloped viruses $(1.43+/-0.67 \mathrm{log}$ reduction). Among vaccinees, CD8 VIA correlated with HIV-1 specific CD107a expression; and weakly with IFNgamma expression. No correlations were observed with CD8 ${ }^{+}$cell expression of IL-2, TNF-alpha, or MIP-1 beta. Virus inhibition by sorted cells was absent from naive $\mathrm{CD}^{+} \mathrm{T}$ cells; the predominant activity was from central and early effector memory populations.

\section{Conclusion}

CD8-mediated virus inhibition, as measured in a 3-day assay with early transmitted reporter viruses, was present in HIV-1+ subjects and vaccinees. Among HIV-1+ subjects, the activity was most robust in virus controllers. Virus suppression correlates most strongly with CD107a, and may come primarily from central memory populations. These data provide insight into the mechanisms of viral inhibition, and suggest that functional analyses of $\mathrm{CD} 8+\mathrm{T}$ cell mediated virus inhibition could identify benchmarks for successful T-cell directed vaccine strategies. 